\title{
Avaliação cefalométrica do perfil mole de pacientes face longa submetidos à cirurgia ortognática: estudo retrospectivo
}

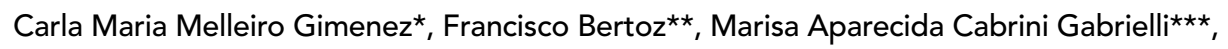

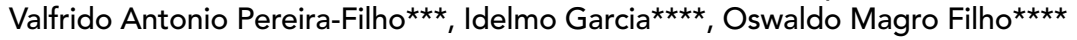

\begin{abstract}
Resumo
Objetivo: o presente trabalho propôs-se a comparar o perfil tegumentar pós-operatório de pacientes Classe II, Padrão Face Longa, submetidos ao tratamento ortodôntico-cirúrgico, com os parâmetros descritos na análise cefalométrica de Legan e Burstone. Metodologia: 32 telerradiografias pós-cirúrgicas, com um mínimo de 6 meses de acompanhamento, foram submetidas a traçado manual (repetido 4 vezes) e digitalização (também repetida 4 vezes) no programa DFPlus para análise cefalométrica. Resultados: os resultados permitiram verificar que 9 das 11 medidas avaliadas encontravam-se estatisticamente diferentes da norma avaliada; contudo, ao se verificar o desvio padrão permitido na norma, os achados deste trabalho situam-se dentro da mesma, com exceção do ângulo mentocervical. Conclusões: as condições experimentais deste estudo permitiram concluir que, embora a população estudada tenha obtido resultados estéticos-funcionais satisfatórios, não se enquadrou nas normas da análise de Legan e Burstone, o que indica que a avaliação após a cirurgia ortognática deve ser principalmente clínica e que a estética facial não está totalmente relacionada com as medidas préestabelecidas na análise cefalométrica.
\end{abstract}

Palavras-chave: Cefalometria. Cirurgia bucal. Face. Ortodontia.

\section{INTRODUÇÃO}

O tratamento ortodôntico-cirúrgico tem como objetivo primário corrigir as deficiências funcionais e promover uma relação equilibrada e harmoniosa dos componentes dentoesqueléticos, considerando também a importância dos tecidos moles na composição da estética do complexo facial. Isto requer que o cirurgião e o ortodontista tenham uma perspectiva de resposta em relação ao tecido mole, de acordo com os diferentes vetores de movimento esqueléticos possíveis para o desenvolvimento das estratégias de tratamento, maximizando assim a possibilidade de obtenção da estética facial esperada ${ }^{26}$.

A face longa é uma deformidade com envolvimento esquelético, de prognóstico desfavorável em termos de metas de correção ortodôntica e estabilidade, que interfere intensamente na qualidade fun-

* Mestre em Ortodontia pela Faculdade de Odontologia de Araçatuba - UNESP. Doutoranda em Odontologia, área de concentração em Ortodontia

pela FOA-UNESP.
** Professor Titular da Disciplina de Ortodontia da Faculdade de Odontologia de Araçatuba - UNESP.

*** Professor Assistente Doutor da Disciplina de Cirurgia e Traumatologia Buco-Maxilo-Facial da Faculdade de Odontologia de Araraquara - UNESP.

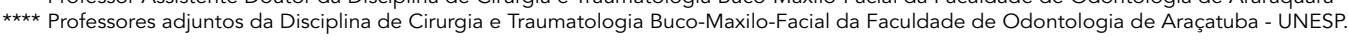


cional do sistema estomatognático e na percepção estética da imagem individual. Geralmente manifesta-se precocemente, mantendo-se como padrão ao longo de todo o processo de crescimento e desenvolvimento ${ }^{39}$, podendo ou não ter suas características acentuadas com o passar da idade ${ }^{20}$. Esse desequilíbrio vertical pode estar associado às más oclusões de Classe I, Classe II e Classe III ${ }^{48,60}$, contudo é mais comumente observado nos pacientes portadores da má oclusão de Classe II $^{13}$.

A característica predominantemente vertical é descrita na literatura por meio de termos específicos como: Síndrome da Face Longa ${ }^{6,48}$, Tipo Hiperdivergente ${ }^{21,36}$ e recentemente Padrão Face Long $\mathrm{a}^{13}$, sendo incidente em aproximadamente $1,5 \%$ da população mundial ${ }^{21}$.

O diagnóstico de pacientes portadores desse padrão baseia-se nas análises da morfologia facial e da cefalometria. Clinicamente, são observadas as seguintes características: ausência de selamento labial passivo; contração do músculo mentoniano durante o selamento labial; exposição dentária excessiva, tanto em repouso quanto durante o sorriso; exposição gengival exagerada durante o sorriso; o nariz geralmente é longo; as bases alares apresentam-se estreitadas; o aplainamento da região zigomática parece maior que o normal; aumento do terço inferior da face, não existindo proporcionalidade que transmita uma percepção harmoniosa do conjunto facial ${ }^{1,18,48,51}$.

Cefalometricamente, observa-se que a forma do contorno facial é alterada, os arcos dentários geralmente são estreitos, a maxila pode ou não se apresentar bem posicionada em relação à base do crânio, enquanto a mandibula geralmente sofre rotação póstero-inferior. Apresentam-se aumentadas as seguintes medidas: a altura facial total e a altura facial inferior e os ângulos sela, articular, goníaco, do plano mandibular e interincisivos e apresentam-se diminuídos o ângulo do eixo facial, assim como o ângulo do perfil e da proporção de altura facial proposta por Jarabak ${ }^{19}$. Tendo em vista esses achados, o tratamento que melhor resulta em harmonia facial e correção da oclusão é a combinação dos procedimentos ortodônticos com a cirurgia ortognática ${ }^{14}$.

Um dos maiores obstáculos para a quantificação das alterações de tecido mole associadas à cirurgia ortognática tem sido a inabilidade de uma análise bidimensional, como a cefalometria, em descrever precisamente estruturas tridimensionais. Devido a esse fato, várias formas de análises voltadas à cirurgia ortognática foram propostas, buscando relacionar adequadamente medidas lineares e angulares. Dentro desse contexto, existe um consenso de que as alterações horizontais são mais previsíveis e mais estáveis que as verticais, o que chama a atenção para o planejamento dos casos de pacientes face longa ${ }^{32,35}$. O conceito de previsão e de controle das alterações do tecido mole em resposta a algum tipo de tratamento teve origem na literatura ortodôntica. Os primeiros estudos produziram médias de proporções relacionando tecidos esqueléticos e tecidos moles, as quais foram empregadas na previsão de várias alterações esqueléticas e dentárias decorrentes do tratamento. No entanto, observou-se que a variabilidade individual é significativa, indicando que vários fatores podem interferir na resposta esperada, os quais não devem ser ignorados ${ }^{5}$.

A maioria dos autores sugere que os tecidos moles estabilizam-se 6 meses após a cirurgia ${ }^{15,17,40,55}$, enquanto outros afirmam que é necessário um período mínimo de 12 meses $^{44,61}$. Além disso, as mudanças no aspecto estético e na oclusão são altamente dependentes da estabilidade alcançada póstratamento ortodôntico-cirúrgico em longo prazo.

Neste contexto, observa-se a necessidade de maiores estudos que contribuam para uma melhor avaliação dos pacientes portadores do Padrão Face Longa, auxiliando o adequado planejamento do tratamento ortodôntico-cirúrgico, e enfatizem também as possibilidades de obtenção de resultados satisfatórios.

\section{PROPOSIÇÃO}

O objetivo deste trabalho retrospectivo foi comparar o perfil tegumentar pós-operatório de 
pacientes Classe II com Padrão Face Longa, submetidos ao tratamento ortodôntico-cirúrgico com os parâmetros descritos na análise cefalométrica de Legan e Burstone ${ }^{32}$.

\section{MATERIAL E MÉTODOS}

\section{Amostra}

Aprovado pelo Comitê de Ética em Pesquisa da Faculdade de Odontologia de Araçatuba-UNESP, Referência Processo FOA no 1284/2003, este estudo analisou as telerradiografias em norma lateral de uma amostra de 32 pacientes adultos submetidos ao tratamento ortodôntico-cirúrgico. Essas radiografias foram provenientes do CEDEFACE (Centro de Pesquisa e Tratamento das Deformidades Buco-Faciais - Araraquara-SP) e da Disciplina de Cirurgia e Traumatologia Bucomaxilofacial da Faculdade de Odontologia de Araçatuba - UNESP, todas realizadas de acordo com a técnica preconizada por Broadbent ${ }^{11}$.

A inclusão na amostra baseou-se nos seguintes critérios:

1) pacientes de ambos os gêneros, leucodermas, brasileiros, dentados, que não se encontravam em fase de crescimento ativo (pacientes adultos);

2) portadores do padrão de crescimento do tipo vertical com características de Face Longa (Tab. 1);

3) relação dentária de Classe II, não apresentando mordida aberta;

4) tratamento ortodôntico-cirúrgico bimaxilar;

5) documentação radiográfica pós-operatória de boa qualidade, quanto à nitidez dos tecidos duros e moles, além do correto posicionamento de cabeça no cefalostato (coluna ereta e Plano Horizontal de Frankfurt paralelo ao solo), assim como adequada documentação fotográfica;

6) técnica ortodôntica de Edgewise convencional para o preparo ortodôntico (Braquetes standard);

7) ausência de outro tipo de cirurgia reparadora estética durante ou após o tratamento ortodôntico-cirúrgico.
Dos 32 pacientes selecionados, 27 pertenciam ao gênero feminino e 5 ao gênero masculino (Gráf. 1), sendo a média de idade de 26,8 anos, variando de 16 a 45 anos (Gráf. 2). A amostra contou com 17 pacientes submetidos à cirurgia de maxila (Osteotomia Le Fort I para reposicionamento superior), mandíbula (Osteotomia sagital para avanço) e mento (Osteotomia para mentoplastia de avanço) e com 15 pacientes que receberam cirurgia de maxila (Osteotomia Le Fort I para reposicionamento superior) e mandíbula (Osteotomia sagital para avanço), o que é descrito no gráfico 3.

\section{Avaliação cefalométrica}

Utilizou-se o programa DF Plus (Dentofacial Show Case) para a avaliação cefalométrica e um único examinador foi responsável pelo traçado e digitalização das telerradiografias.

Empregando-se papel Ultraphan e lapiseira Pentel $0,5 \mathrm{~mm}$, traçou-se sobre o negatoscópio 4 vezes cada telerradiografia (de forma alternada e

Tabela 1 - Características avaliadas do Padrão Face Longa.

\footnotetext{
1. altura facial ântero-inferior aumentada em relação ao terço

médio da face (G'-Sn'/Sn'-Pg'- proporção $<1)$

2. crescimento predominante no sentido vertical $\left(\mathrm{SnGoMe}>33^{\circ}\right)$

3. excesso vertical de maxila (Stms $-1>4 \mathrm{~mm}$ )

4. ausência de selamento labial passivo em posição de repouso (Stms-Stmi > $2 \mathrm{~mm}$ )

5. mandíbula retroposicionada ou deficiente $(\mathrm{G}-\mathrm{Pg} \leq 4, \mathrm{G}-\mathrm{Sn}$ -

$\left.\mathrm{Pg} \leq 8^{\circ}\right)$

6. linha mento-pescoço reduzida $(\mathrm{Sn}-\mathrm{C} / \mathrm{C}-\mathrm{Gn}<93 \mathrm{~mm})$

7. excesso de exposição dos incisivos superiores com os lábios em repouso (Stms $-1>4 \mathrm{~mm}$ )

8. excesso de exposição gengival durante 0 sorriso (maior que $5 \mathrm{~mm}$ )
}

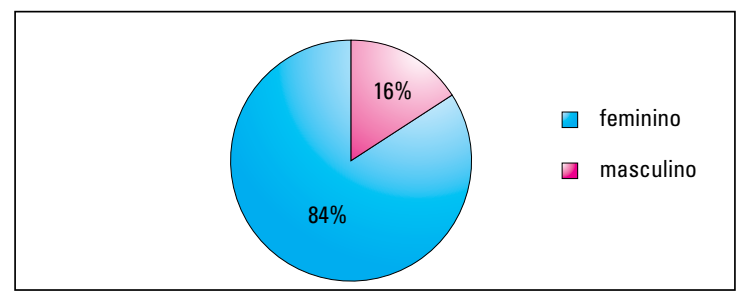

GRÁFICO 1 - Distribuição da amostra analisada segundo o gênero. 


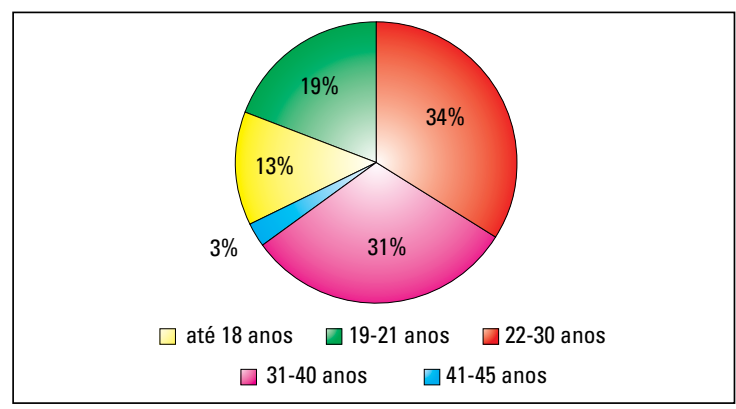

GRÁFICO 2 - Distribuição da amostra analisada segundo a faixa etária.

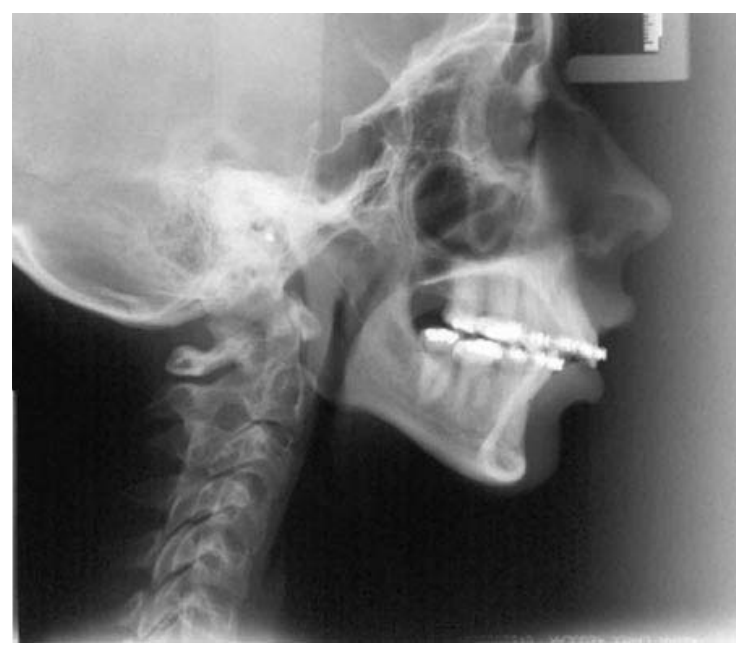

FIGURA 1 - Telerradiografia pré-operatória de paciente Padrão Face Longa.

com intervalos semanais, a fim de evitar a memorização de cada traçado) em ambiente com luminosidade controlada (sala escurecida), marcando-se 71 pontos da análise de Ricketts (porque o programa DF Plus pede a leitura desses pontos para fornecer os traçados da análise de Legan e Burstone). O último traçado de cada paciente foi utilizado como guia para a digitalização ordenada e seqüencial dos pontos cefalométricos no programa Dentofacial Planner Plus (DF Plus). A digitalização de cada traçado também foi repetida 4 vezes (de forma alternada e com intervalos semanais, a fim de evitar a memorização de cada traçado).

Estabeleceu-se a correção de 8\% para o erro de magnificação das imagens, o que foi baseado num

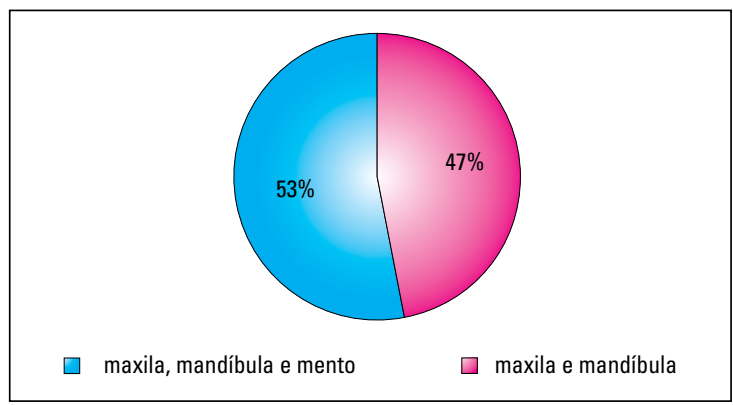

GRÁFICO 3 - Distribuição da amostra analisada de acordo com o envolvimento cirúrgico.

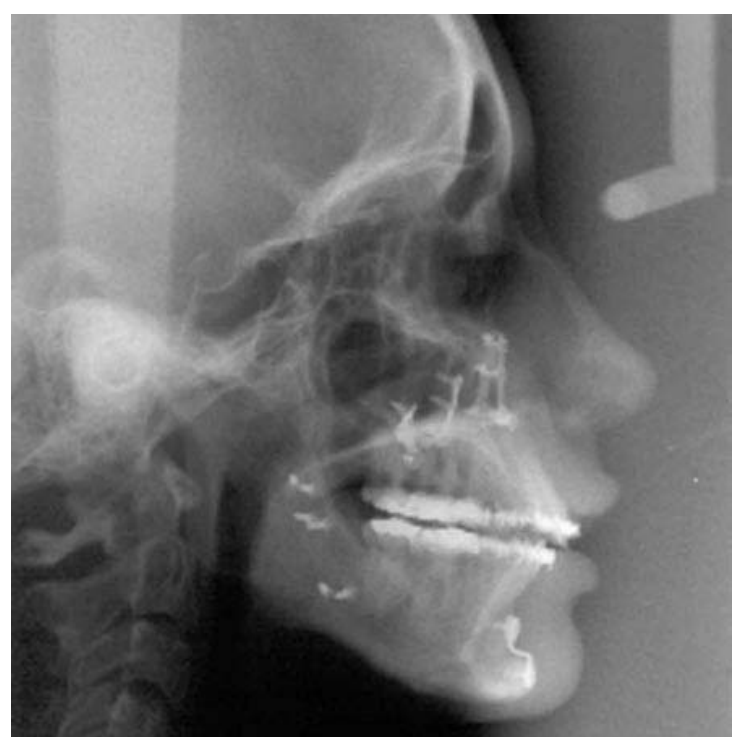

FIGURA 2 - Telerradiografia pós-operatória de paciente Padrão Face Longa.

teste realizado previamente à etapa experimental com uma esfera metálica. Este teste consistiu em medição do diâmetro da esfera metálica e comparação, por meio de regra de três, com seu tamanho na telerradiografia realizada no aparelho de raios $\mathrm{X}$ da FOA-UNESP, no qual foram realizadas as telerradiografias em norma lateral selecionadas.

Por fim, os traçados digitalizados (sempre os últimos da seqüência de 4) foram submetidos à análise de Legan e Burstone ${ }^{32}$ para avaliação, de forma a relacionar as alterações observadas no tecido mole durante a fase pós-cirúrgica com a norma padrão dessa análise. 


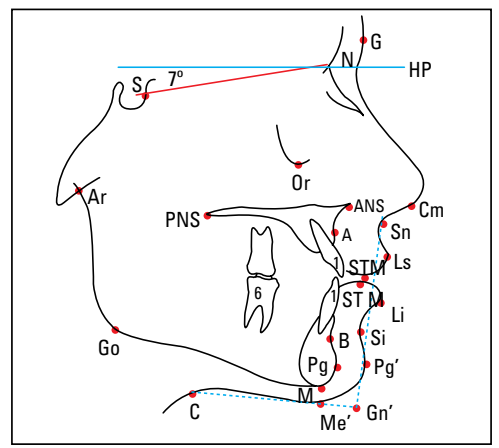

FIGURA 3 - Traçado das estruturas anatômicas pontos utilizados para a análise cefalométrica.

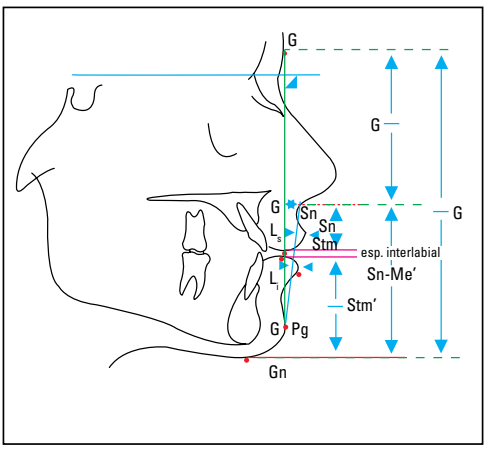

FIGURA 4 - Medidas lineares e proporção facial.

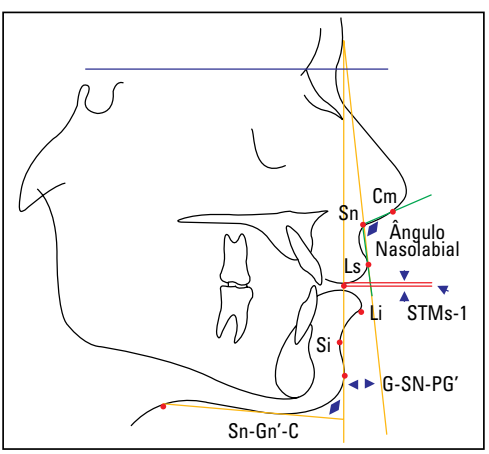

FIGURA 5 - Medidas angulares e exposição do incisivo superior (Stms-1).
Esse mesmo protocolo foi repetido em uma segunda etapa (que não apresentou diferença estatisticamente significante em relação aos valores da primeira etapa), com intervalo de 5 meses da primeira, para que fosse possível realizar a análise estatística do erro do método intra-examinador por meio da regressão linear, o que comprovou ser o método utilizado para a marcação dos pontos cefalométricos e mensuração das medidas angulares e lineares um procedimento confrável e reprodutível. Os resultados apresentados são relativos à primeira etapa experimental. As mensurações da segunda etapa foram utilizadas para apreciação estatística necessária à análise do erro.

\section{Forma de análise dos resultados}

Utilizou-se a análise de Legan e Burstone ${ }^{32}$ para a avaliação cefalométrica dos resultados do tratamento ortodôntico-cirúrgico e a comparação com a norma considerada padrão.

As seguintes medidas foram verificadas (Fig. 4, 5):

- Ângulo da convexidade facial (G-Sn-Pg): $12 \mathrm{~mm}( \pm 4)$;

- Posicionamento ântero-posterior da maxila (G$\mathrm{Sn})$ : $6 \mathrm{~mm}( \pm 3)$;

- Posicionamento ântero-posterior da mandíbula (G-Pg'): $0 \mathrm{~mm}( \pm 4)$;

- Proporção terços médio/inferior (G-Sn/ SnPg'): 1;
- Ângulo mentocervical (SnGn-CGn): 100 $( \pm 7)$;

- Ângulo nasolabial (Cm-Sn-Ls): $102^{\circ}( \pm 8)$;

- Protrusão do lábio superior (Ls a Sn-Pg'): $3 \mathrm{~mm}$ $( \pm 1)$;

- Protrusão do lábio inferior (Li a Sn-Pg'): 2mm $( \pm 1)$;

- Sulco mentolabial (Si a Li-Pg'): $4 \mathrm{~mm}( \pm 2)$;

- Exposição do incisivo superior (StmS-1): $2 \mathrm{~mm}$ $( \pm 2)$;

- Distância interlabial (StmS-StmI): 2mm ( \pm 2$)$.

\section{Análise estatística}

Após a coleta dos dados, estes foram tabulados no programa Excel for Windows, ordenadamente, obtendo-se a média, o desvio-padrão e o coeficiente de variação. Posteriormente foram submetidos à análise estatística por meio do teste $t$ de Student para grupos independentes, com nível de significância a 1\% (Programa para Estatística SPSS e Microtab for Windows). A decisão por esse tipo de análise tomou como base as medidas da análise de Legan e Burstone como representativas de populações e, a partir dessa premissa, foi possível realizar a comparação com os dados deste trabalho.

A avaliação do erro do método intra-examinador teve o objetivo de constatar se o método adotado para a realização da etapa experimental desta pesquisa foi confiável e reprodutível. Para isto, foram comparados os resultados das duas digitalizações 
Tabela 2 - Avaliação estatística das medidas propostas.

\begin{tabular}{cccccc}
\hline medida & freq. & padrão & média & d.p. & c.v. \\
\hline G-Sn-Pg & 32 & $12( \pm 4)$ & 16,8125 s & 5,4848 & 32,62334 \\
G-Sn & 32 & $6( \pm 3)$ & 9,90625 s & 5,37172 & 54,42255 \\
G-Pg & 32 & $0( \pm 4)$ & $2,20937 \mathbf{n}$ & 8,29179 & 375,3011 \\
GSn/SnPg & 32 & 1 & 0,90090 s & 0,08963 & 9,94893 \\
SnGn-CGn & 32 & $100( \pm 7)$ & 72,37188 s & 15,9459 & 22,03328 \\
Cm-Sn-Ls & 32 & $102( \pm 8)$ & $99,67813 \mathbf{~ n}$ & 14,92687 & 14,97459 \\
Ls-SnPg & 32 & $3( \pm 1)$ & $4,9 \mathbf{~ s}$ & 1,956132 & 39,92106 \\
Li-SnPg & 32 & $2( \pm 1)$ & 2,80312 s & 3,203072 & 114,2681 \\
Si/LiPg & 32 & $4( \pm 2)$ & 4,78125 s & 1,637354 & 34,24531 \\
StmS-1 & 32 & $2( \pm 2)$ & 3,021875 s & 2,157767 & 71,4049 \\
StmS-Stml & 32 & $2( \pm 2)$ & $3,425 \mathbf{s}$ & 2,921776 & 85,30732 \\
\hline
\end{tabular}

cefalométricas no programa DFPlus, com intervalo de 5 meses entre as mesmas. Essa verificação foi obtida a partir do estabelecimento da regressão linear simples, considerando-se como variável dependente a segunda mensuração das medidas da análise de Legan e Burstone ${ }^{32}$ selecionadas para teste e como variável independente a primeira mensuração das correspondentes medidas.

\section{RESULTADOS}

A tabela 2 mostra as 11 variáveis cefalométricas verificadas, a freqüência de avaliação de cada variável (32 telerradiografias), seus padrões descritos na literatura assim como o desvio padrão, as médias obtidas por este estudo com seus respectivos desvios padrão (d.p.) e seus coeficientes de variação (c.v.). Ainda, pode-se observar a significância estatística obtida com o teste $t$ de Student pareado.

A tabela 3 mostra os valores obtidos com o teste $t$ de Student para grupos independentes (não pareado) e a comparação quanto à significância estatística.

Após a análise dos dados pelo teste $t$ pareado (Tab. 2), foi possivel observar que 9 das 11 medidas avaliadas apresentaram diferença estatisticamente significante $(\mathrm{p}<0,05)$ e que apenas 2 medidas não diferiram estatisticamente da norma avaliada.
Tabela 3 - Avaliação estatística das medidas propostas de acordo com o teste $t$ de Student para grupos independentes.

\begin{tabular}{cccc}
\hline medida & freq. & $\mathbf{T}_{\mathbf{0}}$ & T esperado para $\mathbf{p}(\mathbf{0}, \mathbf{0 1})$ \\
\hline G-Sn-Pg & 32 & 3,85 & $0,0004 \mathbf{~ s}$ \\
G-Sn & 32 & 3,9 & $0,0004 \mathbf{~ s}$ \\
G-Pg & 32 & 0,97848 & $0,6670 \mathbf{~}$ \\
GSn/SnPg & 32 & $*$ & $*$ \\
SnGn-CGn & 32 & 3,51069 & $0,0012 \mathbf{~ s}$ \\
A) Cm-Sn-Ls & 32 & 0,30728 & $0,7538 \mathbf{~}$ \\
Ls-SnPg & 32 & 15,00091 & $0,00001 \mathbf{~ s}$ \\
Li-SnPg & 32 & 2,799157 & $0,0066 \mathbf{~ s}$ \\
Si/LiPg & 32 & 4,066032 & $0,0004 \mathbf{~ s}$ \\
StmS-1 & 32 & 4,234165 & $0,0002 \mathbf{~ s}$ \\
StmS-Stml & 32 & 4,215798 & $0,0002 \mathbf{~ s}$ \\
\hline
\end{tabular}

$\mathrm{s}=$ signific ante, $\mathrm{n}=$ não significante

* Medida que deve ser avaliada segundo o teste t pareado (ver Tab. 2).

Da mesma forma, na análise dos dados com o teste t para grupos independentes confirmou-se estes dados, observando-se também que 9 das 11 medidas avaliadas apresentaram diferença estatisticamente significante $(p<0,01)$ e que apenas 2 medidas não diferiram estatisticamente da norma avaliada.

\section{DISCUSSÃO}

A amostra analisada constituiu-se de 32 indivíduos adultos, leucodermas, brasileiros, de ambos os gêneros, com média de idade de 26,8 anos (16-45 anos), cujas características principais em comum eram apresentar desenvolvimento vertical, Padrão Face Longa, má oclusão de Classe II, excesso vertical de maxila, retrognatismo mandibular e terem sido submetidos ao tratamento ortodôntico-cirúrgico e avaliados por um período mínimo de seis meses após a cirurgia. Essas condições para inclusão na amostra estão de acordo com a caracterização do Padrão Face Longa descrito na literatu-

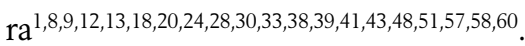

A seleção da amostra foi baseada em análise morfológica facial, tendo em vista estudar o comportamento do perfil tegumentar ante o tratamento ortodôntico cirúrgico, em comparação com as 
normas propostas na literatura por Legan e Burstone ${ }^{32}$, em pacientes que apresentavam um mesmo tipo de padrão de desenvolvimento craniofacial e de má oclusão. A amostra foi limitada ao número 32, pela dificuldade de seleção, principalmente devido a falhas relativas à documentação adequada. No entanto, esse número amostral é considerado suficiente para verificação estatística, de acordo com a justificativa de Moreira ${ }^{37}$. Ao calcular o tamanho de sua amostra para que o erro amostral estatístico ficasse em $5 \%$, esse autor verificou que, para algumas medidas cefalométricas, esse número de pacientes a serem avaliados era exorbitante, tamanha a variabilidade da amostra. Como exemplo citou a medida Pg-NPerp, para a qual seria necessária uma amostra de 1.204 .916 pessoas, a fim de se obter um resultado estatisticamente significante. De suas 52 medidas estudadas, $28(53,8 \%)$ enquadraram-se dentro de um erro de $5 \%$, sugerindo que muitos dados da literatura podem não atingir o tamanho necessário de amostra para um erro de $5 \%$. Quando se verificou a distribuição dessas medidas (28) pelas análises de McNamara Jr. ${ }^{35}$, bem como de Legan e Burstone ${ }^{32}$, foi possível observar que correspondiam a $57,8 \%$ das medidas utilizadas na análise facial com dados isolados, $84,6 \%$ da análise de proporções faciais, $27 \%$ da análise de Legan e Burstone $^{32}$ e 33\% da análise de McNamara Jr. ${ }^{35}$, o que chama a atenção, confirmando conceitos já sedimentados quanto à cefalometria e à análise facial, verificando-se uma porcentagem bem maior de adequação da amostra quando os parâmetros analisados referem-se a proporções faciais $(84,6 \%) \mathrm{em}$ relação a medidas numéricas, sejam elas lineares ou angulares. Esse fato vem ao encontro da afirmativa de Subtelny ${ }^{50}$; Araújo, Tamaki; Arnett, Bergman ${ }^{3}$ e Suguino et al. ${ }^{53}$ sobre a harmonia facial e a estética satisfatória estarem muito relacionadas a proporções adequadas, reconhecendo-se não ser exclusividade de um único tipo de oclusão, muito embora a Classe I assegure condições mais favoráveis para isto ${ }^{8,16,49}$. Estatisticamente, quando são consideradas proporções, estas necessitam de uma amostragem extremamente inferior para fornecer dados conclusivos em relação às referências numéricas angulares ou lineares. Parece lícito considerar que, de acordo com esse ponto de vista, as análises cefalométricas devem ser utilizadas como um complemento da análise facial e não como regra. Hom, Marentette ${ }^{29}$ e Sarver ${ }^{47}$ salientaram ainda o fato de ser provável que, mesmo na análise cefalométrica, o exame de proporções apresente variabilidade menor do que a análise de medidas isoladas.

Observou-se que o gênero feminino foi notoriamente mais numeroso $(84,37 \%)$ que o masculino, na amostra analisada, o que demonstra uma percepção mais crítica da auto-imagem, assim como um maior grau de adesão a esse tipo de tratamento por parte das mulheres. Este fato também está de acordo com a maioria dos relatos da literatura consultada quanto a pacientes com indicação para o tratamento ortodôntico-cirúrgico ${ }^{7,10,12,23}$, embora Suguimoto $^{53}$ tenha encontrado resultados opostos numa amostra de pacientes com indicação ao tratamento ortodôntico combinado com a cirurgia ortognática. Este fato é explicado porque estes pacientes eram fissurados; o que apresenta maior incidência no gênero masculino.

A média de idade encontrada foi de 26,8 anos (16-45), a maior parte dos indivíduos pertencendo à faixa etária de 22 a 40 anos $(65,62 \%)$. Vale notar que, se somarmos ainda a porcentagem de pacientes na faixa etária de 19 a 21 anos de idade, teremos $84,37 \%$ do total. Este dado corrobora os relatos de Bell ${ }^{5}$, Epker ${ }^{18}$ e Boeck et al. ${ }^{10}$ quanto às médias de idade para a procura e aceitação do tratamento ortodôntico cirúrgico por parte dos pacientes e também quanto à época de indicação mais freqüente por parte dos profissionais.

Em relação ao período de acompanhamento pós-cirúrgico, $56,25 \%$ da amostra analisada situaram-se dentro do intervalo de tempo de 6 a 7 meses. Acima desse período de tempo, notou-se dificuldade por parte dos profissionais em manter a freqüência dos pacientes nos retornos de rotina e em conseguir documentar adequadamente a evo- 
lução mais tardia dos casos, o que foi um entrave durante a etapa de seleção da amostra. Embora existam controvérsias na literatura quanto à estabilização dos resultados ortodôntico-cirúrgicos em 6 ou 12 meses, é de consenso geral que a possibilidade de análise desses resultados a partir do sexto mês mostra-se mais aceitável e coerente, visto que este periodo pós-operatório é suficiente para ocorrer uma acomodação satisfatória dos tecidos moles e regressão do edema ${ }^{5,22}$. Assim sendo, optou-se por instituir, como condição para inclusão na amostra deste trabalho, o período mínimo de 6 meses de acompanhamento pós-operatório. $\mathrm{O}$ trabalho de Hack et al..$^{27}$ ilustra esse fato, pois, ao verificarem a estabilidade de seus resultados, revelaram que as maiores alterações do tecido mole se estabeleceram no primeiro ano após a cirurgia. Mudanças significantes $(>10 \%)$ continuaram acontecendo para o ponto subnasal, lábio inferior, protrusão labial superior e inferior e convexidade do perfil mole durante os 5 anos subseqüentes. A estabilidade relativamente baixa em longo prazo das previsões de tecido mole sugere que esses movimentos podem ser independentes do tecido esquelético ao longo do tempo. No entanto, concluiu-se que os valores de previsão de um ano de acompanhamento foram similares aos valores de 5 anos e que poderiam ser utilizados sem maiores implicações no plano de tratamento ortodôntico-cirúrgico. Bailey et $\mathrm{al}^{4}$, trilhando a mesma linha de pesquisa, ressaltaram que freqüentemente supõe-se que as alterações de tecido mole resultantes da cirurgia ortognática se estabelecem por volta dos 6 aos 12 meses após o ato cirúrgico. Verificaram que as alterações de tecido mole que ocorreram entre 1 a 3 anos ou entre 1 a 5 anos após a cirurgia não mostraram diferença significante na média anual de modificação.

Tratando-se da distribuição da amostra quanto ao envolvimento estrutural e à indicação cirúrgica, observou-se que $53,12 \%$ dos indivíduos avaliados foram submetidos à cirurgia ortognática envolvendo maxila, mandíbula e mento e que $46,87 \%$ dos indivíduos receberam indicação cirúrgica de maxila e mandíbula. Este fato pode ser explicado pela premissa de que todos os pacientes selecionados enquadravam-se nas características comuns do Padrão Face Longa Classe II, sendo a mentoplastia, nesses casos, indicada com o intuito de melhorar a percepção da linha cervical e do pogônio nos avanços mandibulares ou de promover uma diminuição da altura facial anterior ${ }^{22}$. Visto que todos os pacientes no pós-operatório apresentaram resultados estéticos satisfatórios e harmoniosos, para a avaliação, esses pacientes foram considerados conjuntamente, e não em grupos separados, pelo fato de todos terem recebido cirurgia ortognática bimaxilar.

Legan e Burstone ${ }^{32}$ extraíram sua análise dos dados obtidos pela observação de uma amostra composta por 40 pacientes leucodermas adultos (20 indivíduos do gênero masculino e 20 indivíduos do gênero feminino), com idade variando de 20 a 30 anos, todos portadores de oclusão normal, com ausência de tratamento ortodôntico. Os autores buscaram estabelecer padrões de normalidade para a análise dos tecidos moles faciais por meio da seleção de medidas e proporções que exprimissem condições para o equilíbrio facial. A seleção da análise de Legan e Burstone ${ }^{32}$, para a avaliação cefalométrica deste estudo, justifica-se por ser uma análise conhecida e consagrada no meio acadêmico, tendo sido utilizada por vários pesquisadores quando da necessidade de avaliação de pacientes com indicação para o tratamento ortodôntico-cirúrgico $2,30,35,37,62$, por fornecer informações precisas para o diagnóstico, planejamento e reavaliação das características individuais.

Do ponto de vista cefalométrico, avaliou-se sistematicamente cada mensuração referente à análise selecionada, submetidas ao teste $t$ de Student para dois grupos independentes, o qual comparou as medidas pós-tratamento com as normas estabelecidas pela análise de Legan e Burstone ${ }^{32}$. Foi indicado esse teste estatístico pelo fato de esses autores utilizarem em sua amostra apenas 40 indivíduos. Em termos estatísticos, esse grupo, em função de sua limitação, não pode ser considerado estatisticamente representativo de uma população. Em outras pala- 
vras, a comparação entre esses valores e os descritos no presente estudo necessitou de uma correção de acordo com o volume amostral (graus de liberdade). Assim, foi possivel empregar os dados da análise cefalométrica selecionada como grupo controle, do tipo histórico, para referência.

Vários autores sugerem que os fatores de variabilidade relativos ao tecido mole (como espessura, tonicidade do tecido mole, forma, solicitação funcional e espaço funcional livre) sejam considerados com cautela na interpretação dos resultados ${ }^{23,31,41}$.

A análise do tecido mole, tendo em vista a cirurgia ortognática, é proposta para auxiliar os ortodontistas e cirurgiões no estabelecimento do plano de tratamento. Os objetivos da cirurgia ortognática são múltiplos e incluem a melhora da estética facial, uma boa relação entre as bases ósseas para suportar os dentes e o estabelecimento de uma função apropriada. A análise cefalométrica é particularmente importante na determinação do que deveria ser mais desejável na estética facial. Os padrões normativos não representam nada mais do que médias de uma população heterogênea que não foi separada por gênero, ascendência étnica ou racial; representam a face média do adulto jovem americano. Seria um erro admitir que todos os pacientes devem ser tratados de acordo com essas médias para que se alcance uma boa estética facial. Não se deveria esquecer, entretanto, que cada paciente poderia ter um conceito diferente de estética facial baseado na origem étnica, familiar ou racial ou em preferências pessoais. Portanto, o planejamento da estética facial é tanto uma ciência quanto uma arte. Apesar dos padrões apresentados serem de grande valia na determinação do procedimento cirúrgico necessário, seria um erro utilizá-los de tal maneira que faces semelhantes sejam produzidas sem variações entre os pacientes ${ }^{62}$.

Normalmente o perfil facial total demonstra discreta convexidade, o que é representado na análise selecionada pelo ângulo da convexidade facial (G-Sn-Pg), que tem como norma $12^{\circ}$. Se este valor mostrar-se alterado, deve-se investigar em qual estrutura encontra-se o problema: na maxila, na mandíbula ou em ambas. Nesta pesquisa, os pacientes selecionados apresentavam no pós-operatório, o perfil mais convexo $\left(16,8125^{\circ}\right)$, o que foi estatisticamente significante em relação ao padrão adotado $\left(12^{\circ}\right)$. No entanto, se for considerada a variabilidade aceitável $( \pm 4)$, essa diferença torna-se compativel com a norma adotada. Clinicamente, os dados nos permitem admitir terem sido obtidos bons resultados estéticos na fase pós-cirúrgica, independentemente dos resultados cefalométricos. Isso confirma que a cefalometria deve ser encarada como um método de diagnóstico complementar.

O ponto subnasal fica $6 \mathrm{~mm}$ à frente da glabela, quando medido a partir do plano de referência horizontal, e o pogônio mole situa-se diretamente sobre ele. No presente estudo, o primeiro apresentou diferença estatisticamente significante em relação ao padrão da análise adotada e o segundo não apresentou diferença estatisticamente significante com o padrão proposto. Na média, o plano horizontal vai situar-se paralelamente a um plano postural horizontal. Para cada paciente, no entanto, é desejável checar a postura horizontal para a adequada avaliação em relação ao plano horizontal. Isso é relevante, visto que a desarmonia facial pode ser diagnosticada até por leigos e o que é visualizado é a convexidade total da face, a relação do subnasal e mento, do mento com os lábios, o nariz e o pescoço. Por essa razão, deve-se também checar o ângulo nasolabial que, em nossos resultados, não apresentou diferença estatisticamente significante com o padrão da análise e a relação queixo-pescoço, medida esta que foi significantemente diferente do padrão. Entretanto, os perfis desses pacientes na análise facial não foram prejudicados, o que vem, mais uma vez, corroborar o fato da cefalometria ser apenas complementar ao diagnóstico clínico. É importante salientar que a porção labial é a última região a ser referendada quanto à redução do edema.

A protrusão do lábio inferior não apresentou diferença estatisticamente significante com a norma da análise selecionada, enquanto a protrusão do lábio superior apresentou diferença estatisticamente signi- 
ficante. Para que se estabeleça a relação de protrusão ou retrusão do lábio superior, é importante recorrer ao ângulo nasolabial. Se a maxila encontrar-se deslocada anterior ou posteriormente, isso influenciará esse ângulo, o que deve ser verificado quanto ao resultado estético. Devemos também referendar que o ângulo nasolabial pode ser modificado por meio de cirurgias nasais ou alterações da posição ou inclinação axial dos incisivos superiores, o qual, como já foi afirmado, não apresentou diferença estatisticamente significante com a norma avaliada.

Para a determinação da posição mandibular, a referência mais importante é a distância entre o pogônio mole e o pescoço. A relação altura/profundidade vertical inferior ( $\mathrm{Sn}-\mathrm{Gn} / \mathrm{Gn}-\mathrm{C}$ ), tomada juntamente com a relação da altura facial inferior (G-Sn/SnPg), pode indicar se o mento localiza-se mais para anterior ou posterior. No presente estudo, essas medidas apresentaram diferença estatisticamente significante com a norma cefalométrica adotada. Tradicionalmente, os estudos cefalométricos têm medido a discrepância mandibular com outras estruturas faciais anteriores, comparando o quanto o mento está posicionado para anterior ou posterior em relação ao Násio ou Glabela.

Os fatores relacionados com o tecido mole tornam-se muito importantes no diagnóstico e tratamento dos problemas que envolvem discrepâncias verticais. Normalmente as proporções esqueléticas são utilizadas para estabelecer a discrepância na altura facial inferior. Por exemplo, a referência ENAPg em relação à N-Pg quantifica a proporção entre a altura facial inferior e a altura facial total. Não há uma relação vertical constante entre o subnasal e a espinha nasal anterior, infelizmente, e ocorre variação do tecido mole na região mentoniana. É por esta razão que uma medida de tecido mole representa o indicador mais confiável de qualquer discrepância vertical. Deve-se também considerar a relação entre a altura facial inferior $(\mathrm{Sn}-\mathrm{Pg})$ e a profundidade facial total $(\mathrm{Pg}-\mathrm{C})$, medida do queixo ao pescoço. É muito provável que o leigo, ao avaliar a dimensão vertical do perfil, compare a altura facial inferior com a distância do mento ao pescoço, em vez de proporcionar mentalmente o terço superior ao terço inferior da face.

No que tange a relação funcional, o espaço interlabial determinará se a altura facial é adequada para o indivíduo. Normalmente, com os lábios em repouso e a mandíbula em oclusão cêntrica, existe um pequeno espaço vertical entre os lábios superior e inferior, que é o chamado espaço interlabial. É necessária uma contração suave dos lábios para o vedamento labial e selamento anterior. A avaliação labial funcional independe das medidas de dimensão vertical e provavelmente tem um grande significado na determinação do plano de tratamento. Se um paciente apresentar o terço facial inferior aumentado, medido cefalometricamente tanto pelas medidas de tecido mole como de tecido esquelético, mas também possuir um espaço interlabial normal, estará contraindicada a redução da dimensão vertical. Se esta redução for realizada, ocorrerá um excesso de comprimento labial, levando à eversão labial na grande maioria das vezes; porém, se houver necessidade de cirurgia para encurtamento do excesso vertical, medidas adequadas deverão ser tomadas. Os resultados deste estudo apresentaram diferença estatisticamente significante dessa mensuração em relação ao padrão adotado. Contudo, se a oscilação for considerada aceitável, os resultados apresentam-se dentro do intervalo preconizado por Legan e Burstone ${ }^{32}$.

Visto que o comprimento do lábio superior é praticamente inalterado durante o tratamento, ele é considerado como guia para o reposicionamento vertical dos incisivos superiores ${ }^{2}$. No entanto, se o lábio superior for muito curto, pode não ser possível ou desejável mudar o nível ou o ângulo do plano oclusal, de modo a estabelecer uma relação normal dos incisivos com o lábio superior. No presente estudo, observou-se que a média de exposição do incisivo superior obtida na fase pós-cirúrgica (mais de $3,02 \mathrm{~mm}$ ) foi estatisticamente diferente da norma estabelecida, mas, levando-se em conta a variação descrita pela análise selecionada, ainda permanece dentro do que se considera normal, assim como 
nos resultados de Moreira ${ }^{37}$. Em sua tese, Moreira ${ }^{37}$ verificou se as análises de Legan e Burstone ${ }^{32}$ e de McNamara ${ }^{35}$ poderiam fornecer informações confiáveis quando aplicadas a uma amostra de pacientes com estética facial agradável (modelos profissionais), independentemente da oclusão e tipologia facial. Observa-se que os dados com maior probabilidade de alterações são os relacionados ao terço facial ântero-inferior e que a razão principal para isso é que as análises geralmente são empregadas clinicamente, independentemente do padrão facial. Das 11 medidas avaliadas pela análise de Legan e Burstone ${ }^{32}, 5$ $(45,4 \%)$ apresentaram diferenças estatisticamente significantes ao nível de $5 \%$, todas relacionadas com o terço inferior da face. Essa variabilidade refere-se a parâmetros relativos ao posicionamento do lábio inferior, à distância interlabial, ao relacionamento entre as porções superior e inferior do terço inferior da face e à proporção dos terços médio e inferior da face em tecidos moles. Vale notar que os resultados desses autores, assim como os deste estudo, não apresentaram diferença estatisticamente significante em relação ao ângulo nasolabial; mas que, por outro lado, as medidas para os $2 / 3$ inferiores do terço inferior da face apresentaram diferença significativa estatisticamente, sugerindo que essa possibilidade deveria ser considerada quando da aplicação da análise cefalométrica no planejamento ortodôntico-cirúrgico. Esses resultados ilustram o fato de que uma boa estética facial é resultado de uma série de componentes que, combinados, produzem um rosto harmonioso, tais como: tipo de oclusão, forma do esqueleto, variações dos tecidos moles, formas do cabelo, expressão facial, altura corporal, percepção do examinador. Todos esses fatores reunidos tendem a contribuir para uma face agradável e esteticamente aceitável. A complexidade da estética facial é tamanha que, mesmo na presença de fatores adequados, o resultado pode não ser favorável, enquanto em alguns casos a presença de poucas características favoráveis já é suficiente para produzir um resultado estético satisfatório.

Quanto aos resultados deste estudo, de uma for- ma geral, vale notar que, mesmo para as medidas que apresentaram diferença estatisticamente significante com o padrão cefalométrico preconizado como norma por Legan e Burstone ${ }^{32}$, se considerarmos a variação admitida pelos autores, pode-se observar que as diferenças são muito discretas e mostram-se clinicamente aceitáveis. Nossos dados corroboram o trabalho de Wylie et al. ${ }^{59}$, o qual mostrou que $60 \%$ dos valores pós-cirúrgicos obtidos não foram aprovados por cinco análises cefalométricas (Epker e Fish; McNamara; Di Paolo; Legan e Burstone, Butow), embora clinicamente estes resultados tenham sido satisfatórios, tanto para os profissionais quanto para os pacientes. Confirma-se assim a premissa de que a avaliação clínica deve prevalecer à cefalometria, porque um perfil equilibrado pode não se enquadrar perfeitamente às normas cefalométricas, que nada mais são do que médias avaliadas em pesquisas anteriores. Estas podem nos direcionar, mas o paciente deve ser visto de forma individualizada.

A análise estatística do erro do método comprovou que a técnica cefalométrica utilizada neste trabalho, para a marcação dos pontos cefalométricos e mensuração das medidas angulares, lineares e da proporção, mostrou-se confiável e reprodutível, o que confirma as considerações de Martins ${ }^{34}$ e Trajano et al. ${ }^{56}$

\section{CONCLUSÃO}

Com base nos resultados obtidos com a metodologia empregada nesta amostra, submetida ao tratamento ortodôntico-cirúrgico, e decorrido um período de seis meses ou mais após a cirurgia ortognática, as avaliações cefalométricas para análise dos tecidos moles, realizadas tomando-se como padrão ouro as grandezas estipulados por Legan e Burstone ${ }^{29}$, permitem concluir que os valores encontrados não estão de acordo com os padrões estipulados, embora clinicamente todos os casos tenham sido considerados estética e funcionalmente satisfatórios.

Enviado em: novembro de 2004 Revisado e aceito: outubro de 2005 


\title{
Cephalometric evaluation of the soft tissue profile in vertical face treated by orthognathic surgery: a retrospective study
}

\begin{abstract}
Aim: to compare the postoperative tegumentar profile of vertical facial growth pattern Class II patients treated by orthognathic surgery approach, in relation with the norms describes in literature on the Legan \& Burstone cephalometric analysis. Methods: thirty two post operatives lateral cephalograms, with a accompaniment minimum of six months was submitted to manual tracing, digitalization on DFPlus program and cephalometric analysis. Results: the results indicated that 9 of the 11 available references was statistically different of the norm, although if examine the admitted pattern deviation on the norm, the basis was placed into the same, exception the chin throat angle. Conclusions: the experimental conditions of this study permit to conclude that although the studied population had obtained satisfactory aesthetic-functional results, the cephalometric values doesn't coincided with that of Legan \& Burstone analysis. Therefore, the postoperative results' assessment must be mainly clinical; and the facial esthetic is not whole relationated with preestablished measurements on cephalometrics analysis
\end{abstract}

Key words: Cephalometry. Buccal surgery. Face. Orthodontics.

\section{REFERÊNCIAS}

1. ANGELILLO, J. C.; DOLAN, E. A. The surgical correction of vertical maxillary excess (long face syndrome). Ann Plas Surg Boston, v. 8, p. 64-70, 1982

2. ARAÚJO, C. U.; TAMAKI, T. Posição labial em repouso e sorriso e a sua relação com os incisivos centrais superiores. Rev Odontol Univ São Paulo, São Paulo, v. 1, n. 2, p. 28-34, 1987

3. ARNETT, G. W. BERGMAN, R. T. Facial keys to orthodontic diagnosis and treatment planning. Part I. Am J Orthod Dentofacial Orthop, St. Louis, v. 103, no. 4, p. 299-312, 1993.

4. BAILEY, L. J.; COLLIE, F. M.; WHITE JR., R. P. Long-term soft tissue changes after ortognathic surgery. Int J Adult Orthodon Orthognath Surg, Chicago, v. 11, no. 1, p. 7-18, 1996

5. BELL, W. H. Modern practice in orthognathic and reconstruc tive surgery. 1th ed. Philadelphia: W. B. Saunders, 1992.

6. BELL, W. H.; McBRIDE, K. L. Correction of long face syndrome by Le Fort I osteomy. Oral Surg Oral Med Oral Path, St. Louis, v. 44 , no. 4, p. 493-520, 1977.

7. BELL, R.; KIYAK, H. A.; JOONDEPH, D. R.; McNEILL, R. W. WALLEN, T. R. Perceptions of facial profile and their influence on the decision to undergo orthognathic surgery. Am J Orthod, St. Louis, v. 88, no. 4, p. 323-332, 1985

8. BITTNER, C.; PANCHERZ, H. Facial morphology and malocclusions. Am J Orthod Dentofacial Orthop, St. Louis, v. 97, no. 4, p. 308-315, 1990

9. BLANCHETTE, M. E.; NANDA, R. S.; CURRIER, G. F.; GHOSH J.; NANDA, S. K. A longitudinal cephalometric study of the sof tissue profile of short and long face syndromes from 7-17 years. Am J Orthod Dentofacial Orthop, St. Louis, v. 109, no. 2 P. 116-131, 1996

10. BOECK, E. M.; GIMENEZ, C. M. M.; COLETA, K. E. D. Prevalência dos tipos de más-oclusões esqueléticas avaliadas em pacientes portadores de deformidades dentofaciais. Rev Dental Press Ortodon Ortop Facial, Maringá, v. 8, n. 4, p. 73-78, 2003

11. BROADBENT, B. H. A new $x$-ray technique and its application to orthodontics. Angle Orthod, Appleton, v. 1, p. 145-166, 1931.

12. CARDOSO, M. A. Estudo das características cefalométricas do Padrão Face Longa. 2003. Dissertação (Mestrado)-Faculdade de Odontologia, Universidade Estadual Paulista, Araçatuba, 2003

13. CARDOSO, M. A.; BERTOZ, F. A.; REIS, S. A. B.; CAPELOZZA FILHO, L. Estudo das características oclusais em portadores de Padrão Face Longa com indicação de tratamento ortodônticocirúrgico. Rev Dental Press Ortodon Ortop Facial, Maringá v. 7, n. 6, p. $63-70,2002$
14. CHACONAS, S. J.; FRAGISKOS, F. D. Orthognathic diagnosis and treatment planning: a cephalometric approach. J Oral Rehabil, Oxford, v. 18, no. 6, p. 531-545, 1991

15. COLLINS, P. C.; EPKER, B. N. The alar base cinch: a technique for prevention of alar base flaring secondary to maxillary surgery. Oral Surg Oral Med Oral Pathol, St. Louis, v. 53, no. 6 , p. $549-553,1982$

16. COX, N. H.; LINDEN, F. P. G. M. van der. Facial harmony. Am J Orthod, St. Louis, v. 60, no. 2, p. 175-183, 1971

17. DANN, J. J.FONSECA, R. BELL, W. A. H. Soft tissue changes associated with total maxillary advancement: a preliminary study. J Oral Surg, Chicago, v. 34, no. 1, p. 19-23, 1976.

18. EPKER, B. N. Superior surgical repositioning of the maxilla: long term results. J Maxillofac Surg, Stuttgart, v. 9, no. 4, p. 237-246, 1981

19. FERREIRA, F. V. Ortodontia: diagnóstico e planejamento clínico. 4. ed. São Paulo: Artes Médicas, 2001

20. FIELDS, H. W.; PROFFIT, W. R.; NIXON, W. L.; PHILLIPS, C.; STANEK, E. Facial pattern differences in long-faced children and adults. Am J Orthod, St. Louis, v. 85, no. 3, p. 217-223, 1984.

21. FITZPATRICK, B. N. The long face and V. M. E. Aust Orthod J Brisbane, v. 8, no. 3, p. 82-89, 1984

22. FONSECA, R. J. Oral and maxillofacial surgery: orthognathic surgery. Philadelphia: W. B. Saunders, 2000.

23. GABRIELLI, M. F. R. Alterações de posição dos tecidos moles da face após osteotomias Le Fort I: um estudo retrospectivo. 1990. Tese (livre-docência)-Faculdade de Odontologia, Universidade Estadual Paulista, Araraquara, 1990.

24. GALLANGHER, D. M.; BELL, W. H.; STORUM, K. A Soft tissue changes associated with advancement genioplasty performed concomitantly with superior repositioning of the maxilla. J Oral Maxillofac Surg, Philadelphia, v. 42, no. 4, p. 238-242, 1984

25. GRABER, T. N. Critical review of clinical cephalometric radiography. Am J Orthod, St. Louis, v. 40, p. 1-26, 1954

26. GUYMON, M.; CROSBY, D. R.; WOLFORD, L. M. The alar base cinch suture to control nasal width in maxillary osteotomies. Int J Adult Orthodon Orthognath Surg, Chicago, v. 3, no. 2, p. 89-95, 1988.

27. HACK, G. A.; MOL van OTTERLOO, J. J.; NANDA, R. Long term stability and prediction of soft tissue changes after Le Fort I surgery. Am J Orthod Dentofacial Orthop, St. Louis, v. 104, no. 6, p. 544-555, 1993.

28. HARALABAKIS, S.; YAGTZIS, S. C.; TOUTOUNTZAKIS, N M. Cephalometric characteristics of open bite in adults: a three dimensional cephalometric evaluation. Int J Adult Orthodon Orthognath Surg, Chicago, v. 9, no. 3, p. 222-232, 1994 
29. HOM, D. B.; MARENTETTE, L. J. A practical methodology to analyze facial deformities. Arch Otolaryngol Head Neck Surg, Chicago, v. 109, no. 5, p. 826-837, 1993.

30. JANSON, G. R.; METAXAS, A.; WOODSIDE, D. G. Variation in maxillary and mandibular molar and incisor vertical dimension in 12-years-old subjects with excess, normal and short lower anteriorface height. Am J Orthod Dentofacial Orthop, St. Louis, v. 106 , no. 4, p. 409-418, 1994.

31. KUYL, M. H.; VERBEECK, R. M. H.; DERMAUT, L. R. The integumental profile: a reflection of the underlying skeletal configuration? Am J Orthod Dentofacial Orthop, St. Louis, v. 106, no. 6, p. 597-604, 1994

32. LEGAN, H. L.; BURSTONE, C. J. Soft tissue cephalometrics for orthognatic surgery. J Oral Surg, Chicago, v. 38, n. 10, p. 744-751, 1980 .

33. LODTER, C.; LAVERHNE, P.; ARNOUD, C. Class II mechanics and overbite. Orthod Fr, Paris, v. 71, no. 3, p. 249-254 2000

34. MARTINS, L. P. Erro de reprodutibilidade das medidas das análises cefalométricas de Steiner e Ricketts pelos métodos convencional e computadorizado. 1993. 121 f. Dissertação (Mestrado)-Faculdade de Odontologia, Universidade Estadual Paulista, Araraquara, 1993.

35. McNAMARA JR., J. A. A method of cephalometric evaluation. Am J Orthod, St. Louis, v. 86, no. 6, p. 449-469, 1984.

36. MOLONEY, F.; WEST, R.; McNEIL, W. R. Surgical correction of vertical maxillary excess: a re-avaluation. J Maxillofac Surg, Stuttgart, v. 10, no. 2, p. 84-91, 1982.

37. MOREIRA, R. W. F. Análise facial e cefalométrica comparativa de mulheres com harmonia facial. 1999. $147 \mathrm{f}$. Tese (Doutorado)-Faculdade de Odontologia, Universidade Estadual de Campinas, Piracicaba, 1999.

38. NANDA, S. K. Growth patterns in subjects with long and short faces. Am J Orthod Dentofacial Orthop, St. Louis, v. 98, no. 3, p. 247-258, 1990

39. NANDA, S. K. Patterns of vertical growth in the face. Am J Orthod Dentofacial Orthop, St. Louis, v. 93, no. 2, p. 103-116, 1988.

40. O'REILLY, M. T. Integumental profile changes after surgical orthodontic correction of bimaxillary dentoalveolar protrusion in black patients. Am J Orthod Dentofacial Orthop, St. Louis, v. 96, no. 3, p. 242-248, 1989.

41. PARK, Y.; BURSTONE, C. J. Soft tissue profile: fallacies of hard tissue standarts in treatment planning. Am J Orthod Dentofacial Orthop, St. Louis, v. 90, no. 1, p. 52-62, 1986.

42. PRITTINEN, J. R. Orthodontic diagnosis of long face syndrome. Gen Dent, Chicago, v. 44, no. 4, p. 348-351, 1996.

43. PRITTINEN, J. R. Orthodontic management of long face syndrome. Gen Dent, Chicago, v. 45, no. 6, p. 568-572, 1997

44. QUAST, D. C.; BIGGERSTAFF, R. H.; HALEY, J. V. The short-term and long-term soft tissue profiles changes accompanying mandibular advancement surgery. Am J Orthod, St. Louis, v. 84 no. 1, p. 29-36, 1983

45. RICKETTS, R. M. The evaluation of diagnosis to computerized cephalometrics. Am J Orthod, St. Louis, v. 55, no. 6, p. 795-803, 1969

46. SANTANA, E.; JANSON, M. Ortodontia e cirurgia ortognática: do planejamento à finalização. Rev Dental Press Ortodon Ortop Facial, Maringá, v. 8, n. 3, p. 119-129, 2003

47. SARVER, D. M. Esthetic orthodontics and orthognathic surgery. St. Louis: Mosby, 1998

48. SCHEDEL, S. A.; EISENFELD, J. H.; BELL, W. H.; EPKER, B. $N$. Superior repositioning of the maxilla: stability and soft tissue: osseous relations. Am J Orthod, St. Louis, v. 70, no. 6, p. 663-674, 1976.

49. SMITH, A.; DERMAUT, L. Soft tissue profile preference. Am J Orthod, St. Louis, v. 86, no. 1, p. $67-73,1984$

50. SUBTELNY, J. D. The soft tissue profile, growth and treatment changes. Angle Orthod, Appleton, v. 31, no. 2, p.105-122, 1961.

51. SUBTELNY, J. D.; SAKUDA, M. Open bite: diagnosis and treatment. Am J Orthod, St. Louis, v. 50, p. 337-358, 1964.
52. SUGUIMOTO, R. M. Avaliação da estabilidade pós-cirúrgica em indivíduos portadores de fissura labiopalatal, submetidos à cirurgia ortognática: estudo cefalométrico através do programa computadorizado CEF-X. 2002. $110 \mathrm{f}$. Tese (Doutorado)-Faculdade de Odontologia, Universidade Estadual Paulista, Araçatuba, 2002.

53. SUGUINO, R. et al. Análise facial. Rev Dental Press Ortodon Ortop Facial, Maringá, v. 1, n. 1, p. 86-107, 1996.

54. THUROW, R. C. Cephalometrics methods in research and private practice. Angle Orthod, Appleton, v. 21, p. 104-116, 1951.

55. TOMLAK, D. J.; PIECUCH, J. F.; WEINSTEIN, S. Morphologic analysis of upper lip area following maxillary osteotomy via the tunneling approach. Am J Orthod, St. Louis, v. 85, no. 6, p. 488-493, 1984.

56. TRAJANO, F. S. et al. Estudo comparativo entre os métodos de análise cefalométrica manual e computadorizada. Rev Dental Press Ortodon Ortop Facial, Maringá, v. 5, n. 6, p. 57-62, 2000.

57. VAN der BEEK, M. C. J.; HOEKSMA, J. B.; ANDERSEN, B. P. Vertical facial growth: a longitudinal study from 7-14 years of age. Eur J Orthod, Oxford, v. 13, no. 3, p. 202-208, 1991.

58. LINDEN, P. M. G. O. Van der. Desenvolvimento das faces longas e curtas e as limitações do tratamento. Rev Dental Press Ortodon Ortop Facial, Maringá, v. 4, p. 6-11, 1999.

59. WIYLIE, G. A.; FISH, L. C.; EPKER, B. N. Cephalometrics: comparison of five analyses currently used the diagnosis dentofacial deformities. Int J Adult Orthodon Orthognath Surg, Chicago, v. 2 , no. 1, p. 15-36, 1987.

60. WOLFORD, L. M.; HILLIARD, F. W. The surgical-orthodontic correction of vertical dentofacial deformities. J Oral Surg, v. 39, no. 11, p. 883-897, 1981

61. WOLFORD, W. M. Lip nasal aesthetics following Le Fort I osteotomy. Discusion ROSEN, H. M. Plast Recontr Surg, Hagerstown, v. 81, p. 2, p. 180-182, 1988.

62. ZINSLY, S. R.; FERRARI JUNIOR, F. M.; SILVA FILHO, O. M. Análise cefalométrica do tecido mole com vistas à cirurgia ortognática. Tradução: Soft Tissue cephalometric analysis for orthognathic surgery.

Endereço de correspondência

Carla Maria Melleiro Gimenez

R. Padre Duarte 989, apto 24 - Centro

CEP:14.801-310 - Araraquara/SP

E-mail: carlamg@yahoo.com 